\title{
O IMINENTE FIM DA IMUNIDADE TRIBUTÁRIA DA INFRAERO (?)
}

\author{
Rayneider Brunelli Oliveira Fernandes ${ }^{1}$
}

\begin{abstract}
RESUMO
Mesmo considerando que a imunidade tributária intergovernamental objetiva afastar eventuais pressões que os entes da federação poderiam exercer entre si de forma recíproca, e assim comprometer a unidade política essencial ao perfeito funcionamento do regime federativo; não se pode excluir a importância da garantia da livre concorrência no mercado. $\mathrm{O}$ presente artigo busca examinar os diversos parâmetros utilizados pela doutrina e pelos tribunais brasileiros para distinguir as empresas estatais que são concessionárias de serviço público daquelas que praticam a atividade econômica. Feito isso, atentar-se-á para o foco deste trabalho, que são os possíveis efeitos que a medida provisória que pretende abrir o capital da INFRAERO, ao ser aprovada, terá no regime tributário dessa empresa, entendida como imune em julgamentos do STF. Este trabalho tem natureza jurídico-interpretativa, com especial atenção ao método jurídico descritivo, visando à decomposição do problema em suas relações e níveis. Portanto, o trabalho foi elaborado a partir do inventário e análise de leis, textos doutrinários e decisões judiciais pertinentes ao tema. Pela natureza das pesquisas jurídicas (como ciência social aplicada), não foi possível ignorar a finalidade propositiva do trabalho. Nesta toada, a partir do questionamento levantado, buscar-se-á propor uma solução jurídica adequada, com vista ao ordenamento brasileiro.
\end{abstract}

Palavras-chave: imunidade; tributos; empresas estatais; serviço público.

\begin{abstract}
Even though the reciprocal tax immunity tends to avoid the federation unities to be compelled to pay taxes ones to others in a reciprocal way, and thus compromising the essential political unity to the functioning of the federative regimen; we cannot exclude the importance of the guarantee of the free competition in the market. This article intends to examine the different parameters that are used by the doctrine and brazilian courts to distinguish the state enterprises that are public utilities from those that practice economic activity. Once it's done, we will attempt to the possible effects that the provisory act that intend to open INFRAERO'S capital, when approved, will present on the this enterprise's tax regimen, understood as immune in the Supreme Court's judgments, as in the appeals 472490/BA and 363.412/BA. This article has juridical-interpretative nature, specially to the juridical descriptive method, aiming to decompose the problem in its relations and levels. Therefore, this article was elaborated from the scroll and analysis of acts, doctrinal texts and judicial decision about the subject. By the nature of legal research (as applied social science), it's unable to ignore the purposeful of this work. In this tune, from the question raised, it will seek to propose an adequate legal remedy, in view of the Brazilian legal system.
\end{abstract}

Key-words: immunity; taxes; state companies; public service.

\footnotetext{
${ }^{1}$ Graduando em Direito pela Universidade Federal de Ouro Preto.
} 


\section{Colocação do problema e hipótese de trabalho}

Em diversas decisões do Supremo Tribunal Federal foi discutida a aplicação da imunidade tributária sobre o patrimônio, serviços e renda da INFRAERO, pois essa prerrogativa era questionada por Municípios que pretendiam impor os tributos de sua competência sobre as manifestações de riqueza dessa empresa.

A Suprema Corte já externou, em reiteradas oportunidades, o entendimento de que a INFRAERO é empresa estatal que presta serviço público em regime de monopólio e, assim, eventual execução porventura contra ela ajuizada deve sujeitar-se, para sua liquidação, ao regime do precatório.

Outro argumento muito apresentado pelos Ministros do STF é o de que a descentralização administrativa não tem o condão de afastar das empresas públicas prestadoras de serviço público a exoneração tributária concernente a impostos.

Deste modo, esse é o entendimento acerca do regime tributário da EMPRESA BRASILEIRA DE INFRAESTRUTURA PORTUÁRIA - INFRAERO com relação à sua imunidade até agora.

A Presidente da República atual vem dando sinais de que irá encaminhar ao Congresso Nacional a proposta de transformar a referida empresa pública em sociedade de economia mista. No entanto, como se verá mais adiante na análise da jurisprudência do STF, tal mudança poderá ter sérias repercussões no que tange ao tratamento fiscal dessa empresa.

Por enquanto o capital da INFRAERO ainda não foi aberto, mas, em virtude da imprescindibilidade de se alcançar agilidade nas obras dos aeroportos, medidas com relação às licitações e à criação da Secretaria de Aviação Civil, ligada agora à Presidência da República, com status de Ministério, foram tomadas.

Assim, de plano, já se percebe alterações substanciais com relação à prestação do serviço público assumido pela INFRAERO. A hipótese que será demonstrada é a de que uma vez aberto o capital da INFRAERO e com terminais de aeroportos brasileiros sendo operados por empresas privadas, não haverá mais que se cogitar em imunidade tributária da empresa supra, porque, em apertada síntese:

não será mais prestado o serviço público em regime de monopólio, já que a prestação também estará nas mãos de agentes privados; 
$>$ terá de ser privilegiada a livre-concorrência, impedindo vantagem competitiva em favor da INFRAERO, atuante a partir de então ativamente no mercado;

a imunidade deixará de ser um benefício essencial para se tornar simples causa de aumento de lucro, não se compatibilizando assim a limitação do poder de tributar da imunidade intergovernamental com sua finalidade primordial, que é o equilíbrio entre os entes federados.

É notável que as modificações na administração interna da INFRAERO poderão repercutir no tratamento da fiscal dessa empresa estatal, justificando deste modo o presente trabalho. Antes de discutir os argumentos que sustentem a presente hipótese, é imprescindível rememorar as suas particularidades.

Para tanto, serão abordados alguns pontos que indispensavelmente circundam a temática. Assim, num primeiro momento, tratar-se-á das empresas estatais e suas relações com os serviços públicos no sistema brasileiro. Depois, serão apresentadas as questões relativas à imunidade recíproca, bem como as divergências que o STF já enfrentou em sede dessa matéria. Finalmente, concentrar-se-á na INFRAERO, para discutir e apresentar a coerência dos argumentos que sustentam a hipótese proposta.

\section{Necessárias noções da temática}

\subsection{As empresas estatais no ordenamento jurídico brasileiro}

As empresas públicas e sociedades de economia mista detêm personalidade de Direito Privado e compõem a Administração Pública Indireta ou Descentralizada conforme o art. $4^{\circ}$, II, "b" e "c" do Decreto-Lei 200/673․ Têm sua criação autorizada, sempre por lei (art. 37,

\footnotetext{
2

Sobre a Teoria do Discurso de Habermas, "argumentos são razões que resgatam, sob condições do discurso, uma pretensão de validade levantada através de atos de fala constatativos ou regulativos, movendo racionalmente os participantes da argumentação a aceitar como válidas proposições normativas ou descritivas" (HABERMAS, Jürgen, 1929- Direito e democracia: entre facticidade e validade, volume I/Jürgen Habermas; tradução: Flávio Beno Siebeneichler. - Rio de Janeiro: Tempo Brasileiro, 1997, p.280 e ss).

${ }^{3}$ BRASIL. Decreto-Lei 200, de 25 de fevereiro de 1967. Dispõe sobre a organização da Administração Federal, estabelece diretrizes para a Reforma Administrativa e dá outras providências. Disponível em: http://www.planalto.gov.br/ccivil/decreto-lei/Del0200.htm. Acesso em: 25 mar. 2011.
} 
XIX, da $\mathrm{CF}^{4}$ ), para desempenhar atividade de natureza econômica, a título de intervenção do Estado no domínio econômico (art. 173 da CF) ou como serviço público ${ }^{5}$ assumido pelo Estado (art. 175 da CF).

É também sociedade de economia mista quando a maioria do capital votante pertence a uma entidade da Administração indireta da pessoa política ${ }^{6}$.

Dito isso, ressalta-se, de plano, que o Decreto-Lei 200/67 faz menção expressa somente à "exploração de atividade econômica". É um aparente desajuste desse diploma com a realidade ${ }^{7}$, pois as empresas estatais tanto podem prestar serviços públicos propriamente ditos, como desenvolver atividades econômicas, conforme preleciona Celso Antônio Bandeira de Mello em sua monografia sobre Prestação de Serviços Públicos e Administração Indireta:

O poder público, invejando a eficiência das sociedades comerciais, tomou de empréstimo os figurinos do direito privado e passou a adotar-lhe os processos de ação, constituindo pessoas modeladas à semelhança delas para a prestação dos mais variados serviços. Quer para prestação de serviços públicos propriamente ditos, quer para o desempenho de atividades de exploração econômica em setores onde se fazia necessária a sua atuação supletiva ou, até mesmo, monopolística, o Estado acolheu o sistema próprio do direito privado. A isto foi impelido tanto pelo objetivo de ganhar mais eficiência quanto, em certos casos, pela natureza peculiar da atividade que, por assim dizer, não se compatibilizaria com outro meio de ação. ${ }^{8}$

4 BRASIL. Constituição Federal de 1988, de 25 de outubro de 1988 . Disponível em: www.planalto.gov.br/ccivil_03/Constituicao/Constituiçao.htm. Acesso em: 04 abril 2011

5 A necessidade do serviço público é tão forte que permeia a implementação do direito à dignidade, fundamento este tido como valor supremo da ordem jurídica. O serviço público é o meio eficaz de generalizar as comodidades fatais à existência sadia da sociedade que antes estavam somente à disposição das camadas sociais mais abastadas. Nesse passo, deve ser ressaltado que não há um direito fundamental de acesso aos serviços públicos, mas sim que os serviços públicos são indispensáveis ao exercício de alguns direitos fundamentais.

${ }^{6}$ Isto é, não se exige que a supracitada maioria seja referente a capital particular, mas tão somente à prevalência acionária votante. Cf., nesse sentido, parecer de Clóvis Ramalhete sobre a qualificação jurídica da Açominas (PARECER N-61. $\quad$ AGU/CGR, $1981 . \quad$ Disponível em: http://www.agu.gov.br/sistmas/site/PaginasInternas/NormasInternas/AtoDetalhado.spx?idAto=7744\&ID_SITE=. Acesso em: 18 abr. 2011).

${ }^{7}$ Eros Grau, na obra Elementos de Direito Econômico, abordando o assunto, comparou a conceituação expressa no DL 200/67 com o tratamento dado à matéria pela Constituição Federal de 1969 em seu art. 170. Nessa análise, o autor, tomando como pressuposto que o DL 200/67 não poderia ter ignorado a inegável existência de empresas estatais prestadoras de serviço público, concluiu que a expressão "atividade econômica" estava sendo usada com duplicidade de sentidos, não admitindo uma oposição entre as ideias que "atividade econômica" e "serviço público" exprimem: "[...] entendo haver plena integração entre tais noções, visto que atividade econômica é gênero na qual se inclui a prestação de serviços públicos." Desse modo, o referido autor pôde argumentar a existência de duas espécies de empresas estatais - as que exploram atividade econômica e as que exploram atividade econômica em sentido estrito. Eros Roberto grau ainda ressalta a importância de se perceber a ambiguidade da expressão "atividade econômica" e que às vezes essa não constatação tem sido responsável por lutas inglórias travadas entre juristas “(GRAU, Eros Roberto. São Paulo: RT, 1981, p. 87 e ss.)

${ }^{8}$ BANDEIRA DE MELLO, Celso Antônio. Prestação de Serviços Públicos e Administração Indireta, 1973, p.88. 
Em relação à personalidade, não importa se prestadora de serviço público ou interventora no domínio econômico, a empresa estatal terá sempre como traço comum o vínculo com o Estado, seu criador, regido por normas de direito público, agindo com recursos hauridos pela coletividade, em razão dos interesses da população, confiados no ente político.

Toshio Mukai, na monografia Direito Administrativo e Empresas do Estado, afirma que há certo desajuste quanto à aplicação da noção de pessoas jurídicas de direito privado com as empresas estatais, nos termos do DL 200/67, como personalidades idênticas às empresas privadas, pois historicamente as empresas do Estado primeiro exerceram serviços públicos industriais (fornecimento de bens e serviços, v.g., água, esgoto), para em momento superveniente, desempenharem atividade econômica stricto sensu.

Nesta trilha, a do Estado intervencionista, Toshio ${ }^{9}$ assume que passa a existir adequação das empresas estatais com a noção de pessoa jurídica de direito privado, pois nesse estágio a presença “[...] do direito público somente se manifesta nas relações com o ente criador, no interesse do controle dos dinheiros públicos envolvidos na exploração da atividade". O referido jurista conclui que "as empresas estatais, portanto, são submetidas a um direito dicotômico, direito diferenciado, composto por normas de direito público mais normas de direito privado $[\ldots]^{\prime 10}$.

\subsection{Serviço público versus atividade econômica stricto sensu}

Para entender melhor a questão, pode ser útil abordar, a priori, a concepção de serviço público no estágio atual do ordenamento jurídico brasileiro, e das diferenças entre atividade econômica e serviço público ${ }^{11}$.

\subsubsection{O serviço público no Brasil - peculiaridades pertinentes do sistema brasileiro}

\footnotetext{
${ }^{9}$ Para ser obter um melhor aprofundamento acerca da matéria, Cf: MUKAI, Toshio. Direito administrativo sistematizado. São Paulo: Saraiva, 1999, 558p.

${ }^{10}$ MUKAI, Toshio. Direito Administrativo e Empresas do Estado. Rio de Janeiro: Forense, 1984, p.124.

${ }^{11}$ Embora tal abordagem não seja relevada por alguns tributaristas, considera-se que não haveria como se falar em imunidade recíproca aplicável a empresas estatais se não soubermos a qualificação da atividade que ela desempenhe, em vista do sistema constitucional adotado referente a essa questão.
} 
A Carta da República distingue serviço público de atividade econômica incumbindo, por meio de seu art. 175, ao "[...] Poder Público, na forma da lei, diretamente ou sob regime de concessão ou permissão, sempre através de licitação, a prestação de serviços públicos”; e atribuindo à esfera privada a exploração de atividade econômica, através do art. 173, enunciando que: "Ressalvados os casos previstos nesta Constituição, a exploração direta de atividade econômica pelo Estado só será permitida quando necessária aos imperativos da segurança nacional ou a relevante interesse coletivo, conforme definidos em lei”"12.

Sob essa ótica, pode-se concluir que somente quando a atividade econômica apresentar a característica originária de serviço público do interesse crucial do povo no desempenho desta pela Administração, o Poder Público poderá executá-la.

Interpreta-se assim que a Constituição não deixou limitada ao simples critério do interesse da coletividade a configuração do serviço público, i.e., não basta que uma atividade apresente relevância social para que seja serviço público.

Também não é de todo restritivo o rol de serviços públicos elencados na Constituição. Os Estados-membros têm competência remanescente, ou seja, poderão incluir em suas respectivas constituições estaduais serviços que a $\mathrm{CR} / 88$ não os confere. $\mathrm{E}$ ainda, os Municípios podem, com fulcro no art. 30, $\mathrm{V}$ da $\mathrm{CF} / 88$, organizar e prestar, direta ou indiretamente, serviços públicos de interesse local (e.g. o serviço funerário), bastando estes estarem previstos na Lei Orgânica do ente. O Distrito Federal reúne as competências estaduais e municipais, estando apenas limitado a não usurpar as federais.

Nesse sentido, pode-se observar que não há diferença com relação à forma de o Estado atribuir a uma autarquia ou empresa estatal a prestação de um serviço público, pois essa deverá ser sempre feita por meio de lei específica.

\subsubsection{A diferença entre serviço público e atividade econômica}

Limitar-se-á a noção de serviço público aos singularmente fruíveis (uti singuli), postergando assim a noção ampla do termo (que também abarcaria os serviços uti universi), consistentes no oferecimento aos cidadãos a prestação de comodidades, de essencial presença

12 BRASIL. Constituição Federal de 1988, de 25 de outubro de 1988 . Disponível em: www.planalto.gov.br/ccivil_03/Constituicao/Constituiçao.htm. Acesso em: 04 abril 2011 
estatal em um dado contexto histórico, determinando a submissão ao regime jurídicoadministrativo.

A remuneração da prestação do serviço público é eminentemente de natureza tributária quando é o ente federado quem o presta. As taxas de serviço, por serem tributos que exigem do Poder Público uma contraprestação (mesmo que potencial), se referem às atividades divisíveis do Estado, e são custeadas pelos que dela se beneficiam. As atividades universais e indivisíveis são financiadas pelos impostos, preponderantemente.

A natureza jurídica da remuneração dos serviços prestados por concessionária de serviço público é de tarifa ou preço público (contratual), consubstanciando em contraprestação de caráter não-tributário, razão pela qual não se submete ao regime jurídico tributário estabelecido para as taxas.

Quanto ao valor da remuneração dos serviços públicos prestados, aplica-se às tarifas o princípio da modicidade. Fruíveis como devem ser, os serviços públicos estão submetidos a uma regulação mais efetiva da Administração quanto à política tarifária. No entanto, o Poder Público não pode também prejudicar a empresa concessionária, que precipuamente visa ao lucro.

No caso das taxas, entende-se que existam diferenças na política de remuneração. Por serem espécies tributárias, decorrem da prestação de serviço público específico e divisível e que têm como base de cálculo o valor da atividade estatal referida diretamente ao contribuinte, pelo que deve ser proporcional ao custo da atividade a que está vinculada, devendo sofrer uma limitação, sob pena de inviabilizar o acesso de muitos a essa comodidade $^{13}$.

O Poder Público tem o dever, nesse sentido, ao contrário do particular que pode agir com indiferença, de procurar, com vista ao princípio da capacidade contributiva (art. $145, \S 1^{\circ}$ c/c art. 5 , LXXVII da CR/88), atender a todos os que buscam fruir dos seus serviços.

A fórmula para distinguir serviço público de atividade econômica não é rígida. É um parâmetro aceitável que no caso das atividades econômicas, flui a regência do princípio da livre iniciativa e da livre concorrência (ao reprimir o abuso de poder econômico no art. 173, $\S 4^{\circ}$ ) atuando o Estado suplementarmente, regulando a atividade, no setor de Direito Privado.

\footnotetext{
${ }^{13}$ Ver jurisprudência nesse sentido: BRASIL, Supremo Tribunal Federal, ADI-MC 1772 MG. Disponível em: http://www.jusbrasil.com.br/jurisprudencia/741055/medida-cautelar-na-acao-direta-de-inconstitucionalidade-adimc-1772-mg-stf. Acesso em 04 abril 2011.
} 
Rememora-se que, embora o Estado possa, “[...] em certos casos previstos na Constituição, atuar personalizadamente na esfera econômica, como protagonista empresarial, as atividades econômicas que, destarte, desempenhe não são qualificáveis como serviços públicos.",14

Ao contrário do pensamento de Jéze ${ }^{15}$, vigora hoje a interpretação dos textos não mais atentada à mens legislatoris, mas à mens legis ${ }^{16}$. Dessa forma, figurará uma atividade como serviço público imprescindivelmente se baseando na realidade social em um dado momento histórico.

Certa norma que define determinada competência material pode ter inúmeras leituras de acordo com as pré-compreensões ${ }^{17}$ de seus intérpretes ${ }^{18}{ }^{19}$. Um exemplo claro é o serviço de telecomunicação. É visível que, desde a promulgação da Constituição, a noção desse serviço se dilatou amplamente, compreendendo cada vez mais meios que possibilitam a comunicação à distância entre os seres humanos.

Por dicção, é atividade econômica aquela que não é resguardada como serviço público, nada importando se é suscetível de lucro ou não. Mesmo assim, considera-se ideal o posicionamento de Celso Antônio Bandeira de Mello, a saber:

Toda exposição feita evidentemente não se propôs, por impossível, a fornecer um arrolamento preciso dos serviços passíveis de se configurarem como públicos, mas sim a atrair atenção para o fato que existem indicações constitucionais claras de que há (a) certos serviços que não podem ser serviços públicos e (b) certos serviços que o são obrigatoriamente ou que (c) podem ser serviços públicos ${ }^{20}$.

\footnotetext{
BANDEIRA DE MELlo, Celso Antônio. Curso de Direito Administrativo. São Paulo: Malheiros. 26 ed., 1102 , p. 686.

${ }^{15}$ Jèze explicita um conceito que atribui ao serviço público uma associação do mesmo com o procedimento de direito público por força da vontade do legislador. Cf.: JÈZE, Gaston. Les principes généraux du droit administratif, Paris: Giard \& Brière, 1936.

${ }^{16}$ A partir do final do século XVIII, a imprescindibilidade da interpretação do legislador foi afastada; desde então, as funções interpretativa e aplicadora das leis foram delegadas aos Tribunais. Luhmann, nesse sentido, disserta que "somente isso torna possível que se possa exigir dos Tribunais decidam todos os casos que lhe são apresentados. A 'vinculação à lei' torna-se assim, por sua vez, objeto da interpretação por parte do Juiz". LUHMANN, Niklas, A posição dos tribunais no sistema jurídico, traduzido por Peter Naumann e revisado por Vera Jacob de Fradera, Revista Ajuris: Porto Alegre, n. 49, ano XII, jul., 1990, p.153.

${ }^{17}$ Cf. HEIDEGGER, Martin. Ser e Tempo, Parte I. Petrópolis: Vozes, 1988.

${ }^{18}$ Cf. GADAMER, Hans-Georg. Verdade e Método. Petrópolis: Vozes, 1997.

${ }^{19}$ A liberdade do intérprete diante da norma é figurada por Hans Kelsen, no último capítulo de sua obra Teoria pura do Direito, rechaçando o formalismo interpretativo tradicional, em que a hermenêutica seria uma atividade intelectiva, consistindo na mera clarificação e compreensão de um único sentido que se poderia deduzir de uma norma (KELSEN, Hans. Teoria Pura do Direito. Trad. de João Baptista Machado. São Paulo: Martins Fontes, 10996).

BANDEIRA DE MELlo, Celso Antônio. Curso de Direito Administrativo. São Paulo: Malheiros. 26a ed., 1102 , p. 689.
} 
É importante então refletir, imaginando que, tomando como conteúdo as atividades, há conjuntos distintos interseccionados: "a" corresponde às atividades econômicas, "b" aos serviços públicos, e "c" é a interseção desses, correspondendo aos elementos comuns.

A flexibilização de monopólios, sobretudo a partir de 1995, refletiu na interpretação do art. 175 da $\mathrm{CR} / 88$, eliminando a titularidade estatal de certas atividades que não podem mais ser consideradas serviços públicos. Destaca-se assim a constante mutabilidade na conformação do serviço público.

Por fim, no que tange ao objeto de pesquisa, é relevante ressaltar que mesmo que não seja nos casos de atividades tidas como serviços públicos somente quando prestadas pelo Estado (serviços que podem ser públicos), que suportam a aplicação dos princípios da livre iniciativa e livre concorrência, o ente federado não pode transformar a realização da atividade numa fonte de riqueza, i.e., num expediente voltado para o acúmulo patrimonial da pessoa política.

Ainda assim, o conteúdo econômico que pode estar por trás do serviço não exime a Administração Pública da obrigação de afastar a finalidade lucrativa da prestação do mesmo ${ }^{21}$.

A exploração de atividade econômica é o expediente ideal para o lucro. Seara dos particulares por excelência, o Estado só as pratica excepcionalmente. Em conformidade com o princípio constitucional da capacidade contributiva, pode-se então concluir, nesse diapasão, que não é a taxa a espécie tributária destinada a compor precipuamente o orçamento do ente federado.

Assentados nesses argumentos ${ }^{22}$,procurar-se-á justificar a aplicação da imunidade tributária recíproca, assunto a ser explorado, por conseguinte.

\subsection{A imunidade tributária recíproca}

\footnotetext{
21 Não se pode confundir aqui finalidade lucrativa com a necessidade de captação de recursos para o aprimoramento do serviço público.

Funda-se em Habermas quando se expõe o presente argumento, defendendo que "as interpretações de casos singulares, que são feitas à luz de um sistema coerente de normas, dependem da forma comunicativa de um discurso constituído de tal maneira, do ponto de vista social-ontológico"; e que coerência aponta para os pressupostos pragmáticos de argumentação. (HABERMAS, Jürgen, 1929- Direito e democracia: entre facticidade e validade, volume I/Jürgen Habermas; tradução: Flávio Beno Siebeneichler. - Rio de Janeiro: Tempo Brasileiro, 1997, p.285). Nesse ponto, destaca-se que a imunidade recíproca para ser aplicada tem de cumprir a sua finalidade.
} 
A Constituição Federal confere aos entes políticos (União, Estados, Municípios e Distrito Federal), ao definir a competência tributária destes, o poder de instituir tributos, que serão exigíveis com as ocorrências dos respectivos fatos geradores. Entretanto, a própria Constituição exclui certos bens, ou serviços, ou pessoas do poder de tributar, deixando-os fora do alcance da tributação. Essas situações materiais que a Carta Republicana não deseja que sejam oneradas por tributos dizem-se imunes ${ }^{23}$.

A Carta da República, no art. 150, VI, trata da imunidade recíproca ${ }^{24}$. Essa limitação do poder fiscal exclui a possibilidade de tributação do patrimônio, renda e serviços de cada ente político (União, Estados, Distrito Federal e Municípios) por quaisquer das entidades federativas. O objetivo dessa norma, de acordo com Luciano Amaro, é a proteção do federalismo; porém, o referido autor também traz o entendimento que "[...] o que se imuniza é o 'patrimônio, a renda e os serviços' dos entes da federação, o que não impede a incidência de impostos indiretos, como o IPI e o ICMS",25.

De forma a estruturar mais claramente o entendimento acerca da questão, pode-se dizer que a imunidade intergovernamental só se aplica quanto os tributos não vinculados, ou seja, aqueles que não pressupõem uma contraprestação estatal.

A imunidade recíproca tem como fundamento, além do princípio do federativo, o princípio da capacidade econômica. Por aplicar todos os recursos hauridos na sua finalidade

23

Para um melhor entendimento acerca das imunidades, Cf: COSTA, Regina Helena. Imunidades Tributárias Teoria e Análise da Jurisprudência do STF, 2001, São Paulo: Malheiros;

${ }^{24} \mathrm{O}$ nascimento da imunidade tributária se dá nos Estados Unidos, a partir do caso Mc Culloch vs. Maryland, no qual, sem expressa previsão constitucional, a doutrina da reciprocal immunity of Federal and State Intrumentalities foi objeto de construção jurisprudencial, com base na teoria dos poderes implícitos (implied powers of the Constitution theory). A União havia fundado um banco nacional (Second Bank of The United States) e o Estado de Maryland instituiu um imposto sobre bancos e filiais de bancos não autorizadas pelo Legislativo estadual. O então Chefe de Justiça da Suprema Corte John Marshall, no acórdão, sustentou que "the power to tax involves the power to destroy" ('o poder de tributar inclui o poder de destruir', tradução nossa), pelo que os meios de ação do governo federal (entre os quais, pela teoria dos poderes implícitos, abarcariam o de regular o sistema financeiro e, para cumprir essa função, instituir um banco nacional) deviam ser imunizados à competência fiscal dos Estados-membros. A falta de previsão expressa da Constituição americana foi assim justificada pelo magistrado Marshal: "Let the end be legitimate, let it be within the scope of the constitution, and all means which are appropriate, which are plainly adapted to that end, which are not prohibited, but consist with the letter and spirit of the constitution, are constitutional" ('Deixe que o fim seja legítimo, deixe-o estar no âmbito da Constituição, e todos os meios que são apropriados, que são claramente adaptados para esse fim, que não são proibidos, mas coerentes com o texto e o espírito da Constituição, são constitucionais', tradução nossa). Posteriormente, a Suprema Corte também estendeu a imunidade aos Estados-membros por tributos federais e, desta maneira, jurisprudencialmente, surgiu, nos Estados Unidos, sem norma constitucional expressa, a imunidade recíproca. Em relação à origem da imunidade tributária, cf: SMITH, Edward Jean, John Marshall: Definer of a Nation, New York: Henry Holt \& Company, 1996.

${ }^{25}$ AMARO, Luciano. Direito Tributário Brasileiro. 12ªd., São Paulo: Saraiva, 2006, p.152. 
essencial, pode-se afirmar que as pessoas jurídicas de Direito Público não tem capacidade contributiva $^{26}$.

Esta prerrogativa, porém, não tem o condão de exonerar as empresas públicas e sociedades de economia mista da obrigação de recolher os tributos, pois, nos termos do $\S 2^{\circ}$ do art. 173 da Constituição, as empresas públicas e as sociedades de economia mista não poderão gozar de privilégios fiscais não extensivos às do setor privado.

Assim, o raciocínio mais pujante é o que as empresas públicas e sociedades de economia mista terão seus respectivos serviços, rendas e patrimônios tributados como qualquer outra empresa privada. Isto acontece porque essas personalidades jurídicas apresentam capacidade contributiva, ou seja, por mais nobre que seja a atividade que elas exploram, não são somente para fins públicos que o patrimônio, renda e serviços delas estão voltados.

Lembrando o que já foi dito, observa-se que o Estado criou empresas estatais não para explorar atividade econômica mas para delegar serviços públicos ou de atos de polícia, sendo verdadeiramente 'longa manus' das pessoas políticas que, por meio de lei, as criam e lhes apontam os objetivos públicos a alcançar. Essa é a situação prevista no art. 175 da CR/88.

Nesse sentido, discute-se: por que devem ser tributadas essas pessoas jurídicas, frutos da descentralização administrativa como expediente destinado a garantir maior eficiência na prestação de serviços públicos, se, numa mesma situação, não seria o ente político se exercesse tal atividade diretamente ou por meio de autarquias? Foi necessária uma correção de juízos normativos para a superação dessa aparente distorção, i.e., uma "[...] aceitabilidade racional apoiada em argumentos.",27

Recorrentemente, tal assunto é debatido nos tribunais e teses são elaboradas. O caso de maior destaque foi o da Empresa Brasileira de Correios e Telégrafos (EBCT); empresa pública da União que em virtude de créditos fiscais constituídos perante certos Estados vinha sofrendo execuções fiscais e tendo seus bens penhorados. Nesses julgamentos, foram debatidos a penhorabilidade dos bens e o reconhecimento da imunidade tributária da $\mathrm{EBCT}^{28}$.

A jurisprudência hoje se posiciona no sentido de que seriam imunes as empresas públicas prestadoras de serviço público monopolizado porque, nesses casos, atinge-se o

\footnotetext{
${ }^{26}$ Não se pode confundir capacidade contributiva com capacidade econômica. Embora no setor público haja يecursos, não existe "sobra" para ser apropriada pelo Poder Público através da imposição de impostos.

HABERMAS, Jürgen, 1929- Direito e democracia: entre facticidade e validade, volume I/Jürgen Habermas; Ł̧̧adução: Flávio Beno Siebeneichler. - Rio de Janeiro: Tempo Brasileiro, 1997, p.281.

Cf. jurisprudência acerca do caso: BRASIL, Supremo Tribunal Federal. RE 568442/RS. Ministra Relatora Cármem Lúcia, julgado em 23/09/2009 In Dje-044 10/02/2010.
} 
objetivo da imunidade recíproca, não havendo dúvidas quanto ao regime jurídico de Direito Público que é aplicado a essas atividades.

Entretanto, tem-se observado nos tribunais o entendimento de que, quando prestadoras de quase qualquer serviço público, as empresas estatais serão abarcadas pela imunidade recíproca do art. 150, VI da CR/88. Desta forma, é de se constatar que alguns desses serviços públicos não são exclusivos de prestação por parte dos entes políticos (e.g. os do art. 21, XII da $\mathrm{CF} / 88$ ) e algumas das atividades desempenhadas por essas empresas estatais não são serviços públicos (v.g. os serviços atípicos dos Correios, como a venda de bilhetes de loteria). Obviamente, estes últimos serviços são tributados normalmente, conforme entendimento jurisprudencial assim ementado numa decisão do TRF da $5^{a}$ região:

TRIBUTÁRIO E PROCESSUAL CIVIL. APELAÇÃO. NÃO RECEBIMENTO QUANTO À PARTE EM QUE NÃO HOUVE SUCUMBÊNCIA. IMPOSTO SOBRE SERVIÇOS. EMPRESE BRASILEIRA DE CORREIO E TELÉGRAFOS. IMUNIDADE EM RELAÇÃO AOS SERVIÇOS POSTAIS POR ELA PRESTADOS. SERVIÇOS NÃO POSTAIS: VENDA DE TÍTULO DE CAPITALIZAÇÃO E LOTERIA. INCIDẾNCIA DO IMPOSTO.

1. Não deve ser recebido o recurso de apelação quanto à questão da impenhorabilidade de bens da ECT E, porquanto reconhecida na sentença, logo não se podendo falar em sucumbência nesse tocante.

2. Ante à dicção do art. 50 da Carta Magna de 1967, com a redação que lhe foi dada pela Emenda Constitucional $\mathrm{n}^{\circ} 1 / 69$, a Lei Complr $\mathrm{n}^{\circ} 56$, de 15.12 .87 - que inclui os serviços postais na lista daqueles sobre os quais incide o ISS - é constitucional, posto que aprovada por voto dos líderes, representando os liderados, de acordo com o art. 372, II, do Regimento Interno do Senado Federal. Precedente antigo da Primeira Turma desta Corte: AC87583, Relator: Desembargador Federal Abdias Patrício Oliveira, DJ de 19/12/1997, pág. 111923, decisão unânime.

3. O egrégio STF cristalizou o entendimento de que os serviços postais explorados pela ECT (previstos como tal e como atividades correlatas nos arts. $7^{\circ}$ e $8^{\circ}$ da Lei n. ${ }^{\circ} 6.538 / 78$ ) constituem serviços públicos de competência da União, não estando a prestação deles sujeita ao ISS, uma vez que o artigo 150, inciso VI, alínea a, da Constituição Federal estabelece imunidade recíproca entre a União, os Estados, o Distrito Federal e os Municípios no que concerne à instituição de impostos sobre os serviços, uns dos outros. Em relação aos serviços não postais, contudo, como a distribuição de carnês de Tele-sena, Papatudo, carnês do Sílvio Santos e outros títulos de capitalização, ou os serviços de distribuição e venda de bilhetes de loteria, etc., devem sofre a incidência daquela exação porquanto não estão no âmbito daqueles de monopólio da União, representando, em verdade, a exploração de atividade econômica. Precedentes, inclusive desta Terceira Turma (AC 122.069 - CE, Rel. Des. Federal Geraldo Apoliano, DJ 22.06.2004).

4. Apelação a que se nega provimento ${ }^{29}$.

\footnotetext{
${ }^{29}$ BRASIL, Tribunal Regional Federal da $5^{\text {a }}$ Região. AC 364578/CE, Rel. Des. Amanda Lucena. Disponível em: http://www.jusbrasil.com.br/jurisprudencia/8339213/apelacao-civel-ac-364578-ce-0024826-4120054050000trf5. Acesso em 28 Abr. 2011.
} 
Essas atividades atípicas dos Correios são tributadas porque a empresa está competindo no mercado, figurando a exação uma proteção ao princípio da livre concorrência.

A livre concorrência está configurada no art. 170, IV, como um dos princípios da ordem econômica. Ela é uma manifestação da liberdade de iniciativa e, para garanti-la, a Constituição estatui que a lei reprimirá o abuso de poder econômico que vise à dominação dos mercados, à eliminação da concorrência e ao aumento arbitrário dos lucros. Os dois dispositivos se complementam no mesmo objetivo. Visam tutelar o sistema de mercado e, especialmente, proteger a livre concorrência contra a tendência concentradora capitalista.

$\mathrm{O}$ art. 173, caput da $\mathrm{CR} / 88$ pretende assegurar a livre concorrência também perante o Estado ao condicionar a exploração direta de atividade econômica pelo Estado exigindo a necessidade aos imperativos da segurança nacional ou a relevante interesse coletivo, conforme definidos em lei.

Infere-se, de acordo com o raciocínio aqui apresentado, que o princípio da livre concorrência, quando não respeitado, não permite a aplicação da imunidade recíproca. A Suprema Corte já exarou decisões nesse sentido ${ }^{30}$, condicionando esta à não ofensa à norma da competitividade, a saber:

Em conclusão, o Tribunal, por maioria, deu parcial provimento a recurso extraordinário interposto pela Companhia Docas do Estado de São Paulo - CODESP contra acórdão do extinto Tribunal de Alçada Civil do referido Estado que entendera serem devidos, pela recorrente, o IPTU e as taxas de conservação e limpeza de logradouro público, remoção de lixo e iluminação pública sobre imóveis que compõem o acervo do Porto de Santos - v. Informativos 405 e 441 . Inicialmente, não se conheceu do recurso relativamente aos artigos 21 , XII, f e 22, X, da CF, por falta de prequestionamento, nem no tocante às taxas, haja vista não se ter apontado o dispositivo constitucional que teria sido inobservado pelo Tribunal a quo, no que estabelecida a legalidade da exigência do tributo desde que os serviços sejam postos à disposição do contribuinte, ainda que não utilizados. No mérito, prevaleceu o voto do Min. Joaquim Barbosa que reputou necessária, para a aplicabilidade da imunidade recíproca à CODESP, a superação dos seguintes estágios: 1) a imunidade seria subjetiva, ou seja, se aplicaria à propriedade, bens e serviços utilizados na satisfação dos objetivos institucionais imanentes do ente federado, cuja tributação poderia colocar em risco a respectiva autonomia política. Em consequência, seria incorreto ler a cláusula de imunização de modo a reduzi-la a mero instrumento destinado a dar ao ente federado condições de contratar em circunstâncias mais vantajosas, independentemente do contexto; 2) atividades de exploração econômica, destinadas primordialmente a aumentar o patrimônio do Estado ou de particulares, deveriam ser submetidas à tributação, por apresentarem-se como manifestações de riqueza e deixarem a salvo a autonomia política; 3) a desoneração não deveria ter como efeito colateral relevante

\footnotetext{
${ }^{30}$ Sobre a relevância da jurisdição, pode-se expor como uma expectativa de aceitabilidade da posição aqui proposta o entendimento de Luhmann, explicitando que: "[...] por intermédio da atividade sentenciadora dos Tribunais um Direito judicial (Richterrecht), que, no decorrer da sua reutilização constante, é, em parte, condensado, isto é, formulado com vistas ao reconhecimento (Wiedererkennung), e, em parte, confirmado, isto é, aproveitável também em outros casos (Sachlagen)." LUHMANN, Niklas, A posição dos tribunais no sistema jurídico, traduzido por Peter Naumann e revisado por Vera Jacob de Fradera, Porto Alegre: Revista Ajuris, n. 49, ano XII, jul., 1990, p.163.
} 
a quebra dos princípios da livre concorrência e do exercício de atividade profissional ou econômica lícita. ${ }^{31}$

Além do requisito do não afrontamento à livre concorrência, outro fator, também relacionado à regra da competitividade, que se lista para obstar o reconhecimento da imunidade tributária recíproca é a criação de uma sociedade de economia mista, podendo ter seu capital negociado na bolsa de valores. Afirma-se isso porque (a referida criação) já traz uma desconfiança óbvia de que o objetivo prestacional está se enrustindo de conteúdo enriquecedor.

Nesse sentido, o Supremo Tribunal Federal ${ }^{32}$ só admitiu a extensão da aplicabilidade da imunidade recíproca às sociedades de economia mista porque a parcela societária dos particulares era ínfima, aparentemente incapaz de possuir ingerência na finalidade prestacional do serviço público; o entendimento acerca da matéria foi assim pontificado:

O Min. Joaquim Barbosa constatou que a recorrente passaria nesses estágios e que o acórdão recorrido teria se equivocado quanto à caracterização da atividade desempenhada por ela. No ponto, citou uma série de precedentes da Corte no sentido de que a exploração dos portos marítimos, fluviais e lacustres caracteriza-se como serviço público. Considerou, em seguida, que confirmariam a lesão à livre iniciativa, livre concorrência e ao dever fundamental de pagar tributos três quadros hipotéticos. Disse que, se a participação privada no quadro societário da CODESP fosse relevante, o intuito lucrativo sobrepor-se-ia à exploração portuária como instrumentalidade do Estado, o que não seria o caso dos autos, já que a União deteria $99,97 \%$ das ações da empresa. Destarte, mantida a relevância da instrumentalidade estatal, não se vislumbraria violação do dever fundamental de pagar tributos e de custeio dos demais entes federados. Aduziu que, por outro lado, os autos não indicariam que a CODESP operaria com intuito primordial de auferir vantagem econômica para simples aumento patrimonial da União. Destacou que, se a CODESP operasse em mercado de livre acesso, o reconhecimento da imunidade violaria os postulados da livre concorrência e da livre iniciativa, mas que isso também não se daria na espécie, haja vista inexistir indicação de que a CODESP tivesse concorrentes em sua área de atuação específica. Reputou, ainda, importante examinar se a propriedade imóvel em questão seria utilizada diretamente pela entidade imune em sua atividade-fim, ou se seria cedida a entidade privada que se destinaria a explorá-la com intuito lucrativo. Observou que a recorrente seria uma instrumentalidade da União, isto é, entidade derivada, criada com a finalidade de executar um mister que a Constituição atribuiu à União. Por fim, asseverou caber à autoridade fiscal indicar com precisão se a destinação concreta dada ao imóvel atenderia, ou não, ao interesse público primário ou à geração de receita de interesse particular ou privado. Assim, reconheceu a imunidade do imóvel pertencente à União, mas afetado à CODESP, utilizado em suas atividades-fim. Vencidos os Ministros Marco Aurélio, Ricardo Lewandowski e Cezar Peluso, Presidente, que desproviam o recurso. Precedentes citados: RE 172816/RJ (DJU de

\footnotetext{
${ }^{31}$ BRASIL, Supremo Tribunal Federal. Informativo no 602. RE 253472/SP, rel. orig. Min. Marco Aurélio, red. p/ o acórdão Min. Joaquim Barbosa, 25.8.2010, grifo nosso. Disponível em: http://www.stf.jus.br/arquivo/informativo/documento/informativo597.htm\#IPTU: Imunidade Tributária Recíproca e Cessão de Uso de Bem Público - 1. Acesso em: 04 de abril 2011

${ }^{32}$ Nesse julgamento, foi suscitada pelo ente tributante, em sua defesa, a Súmula 76 do STF, que enuncia que "as sociedades de economia mista não estão protegidas pela imunidade fiscal [...]”. BRASIL, Supremo Tribunal Federal, Súmula 76 - 13/12/1963 - Súmula da Jurisprudência Predominante do Supremo Tribunal Federal Anexo ao Regimento Interno. Edição: Imprensa Nacional, 1964, p. 58.
} 
13.5.94); RE 356711/PR (DJU de 7.4.2006); RE 253394/SP (DJU de 11.4.2003); RE 265749/SP (DJU de 12.9.2003) ${ }^{33}$.

Dessa maneira, mesmo quando uma mesma empresa estatal explore atividade econômica e serviço público cumulativamente, defende-se a tributação. Dever-se-ia então aplicar a imunidade somente aos serviços, patrimônio e renda afetados à prestação do serviço público.

Se o ente político visar o usufruto da imunidade, deve, portanto, desvincular tudo aquilo possa confundir atividade econômica com o serviço público, pois o objetivo estrito da imunização é permitir o regular exercício das competências materiais das pessoas políticas, que poderiam encontrar óbice na exação de tributos.

Enfim, sustentados os posicionamentos acima expostos, poder-se-á defender efetivamente a tese de que a abertura do capital da INFRAERO terá como efeito colateral o fim da sua imunidade.

\section{A INFRAERO}

Autorizada a sua criação há 38 anos, mediante a Lei n. 5.862/1972, a INFRAERO tem por finalidade implantar, administrar, operar e explorar industrial e comercialmente a infraestrutura aeroportuária, que lhe for atribuída pela Secretaria de Aviação Civil da Presidência da República.

Constituída sob a forma de empresa pública, a INFRAERO recebe da União a competência material constitucional do art. 21, XII, "c". Assim, para a exploração da infraestrutura aeroportuária, setor altamente necessitado de investimentos, o Poder Público, fulcrado no art. $4^{\mathrm{o}}$, I da Lei n. $5.862 / 72^{34}$, fica autorizado a transferir para o patrimônio da INFRAERO os recursos necessários para propiciar o regular funcionamento da atividade institucional desta.

\footnotetext{
33 BRASIL, Supremo Tribunal Federal, RE 253472, 2010, grifo nosso. Disponível em: http://www.stf.jus.br/arquivo/informativo/documento/informativ0597.htm\#IPTU: Imunidade Tributária Recíproca e Cessão de Uso de Bem Público - 1 Acesso em: 04 de abril 2011 34

BRASIL. Lei n. 5.862 de 12 de dezembro de 1972. Autoriza o Poder Executivo a constituir a empresa pública denominada Empresa Brasileira de Infraestrutura Aeroportuária - INFRAERO, e dá outras providências. Disponível em: http://www.planalto.gov.br/ccivil_03/Leis/1970-1979/L5862.htm. Acesso em: 04 abr. 2011.
} 
A INFRAERO opera desde grandes aeroportos brasileiros até alguns que ainda não recebem voos comerciais regulares. Vinculada ao Ministério da Defesa, a INFRAERO administra 67 aeroportos, 69 Grupamentos de Navegação Aérea e 51 Unidades Técnicas de Aeronavegação, além de 34 terminais de logística de carga.

Pede-se licença para fazer uma breve digressão para detalhar, a fim de aclarar as ideias, o serviço público de competência privativa da União navegação aérea, aeroespacial e a infraestrutura aeroportuária, elencado no art. 21, XII, “c” da CR/88 35 .

A exploração de transporte aéreo é delegada às empresas aéreas privadas, tais como, TAM, GOL, OCEANAIR etc. Por outro lado, a exploração aeroportuária é titularizada pela INFRAERO.

O controle do espaço aéreo e a regulação do tráfego aéreo, pela grande relevância que apresentam para a segurança nacional, são prestados diretamente pelo Poder Público.

O serviço de infraestrutura aeroportuária é administrado pela ANAC; o serviço de navegação aérea é gerido também em sua grande parte pela ANAC, com exceção do controle do tráfego aéreo, que é afeto ao Comando da Aeronáutica, através do DECEA (Departamento de Controle do Espaço Aéreo, órgão integrante do Ministério da Defesa). E ainda, fica a cargo do Comando da Aeronáutica a atividade de investigação dos acidentes aeronáuticos do ponto de vista técnico, através do CENIPA.

Embora o serviço público prestado pela INFRAERO possa ser objeto de concessão pela Diretoria da ANAC (agência reguladora que tem a atribuição legal de fiscalizar e regular a infraestrutura aeronáutica civil ${ }^{36}$ ), fulcrada no art. 11 , IV da Lei n. $11.182 / 2005^{37}$, justificase a aplicação da imunidade tributária à referida empresa estatal, conforme reiteradas decisões da Suprema Corte, como a abaixo assim ementada:

INFRAERO. EMPRESA PÚBLICA FEDERAL VOCACIONADA, EM FUNÇÃO DE SUA ESPECÍFICA DESTINAÇÃO INSTITUCIONAL, A EXECUTAR, COMO ATIVIDADEFIM, SERVIÇOS DE INFRA-ESTRUTURA AEROPORTUÁRIA. MATÉRIA SOB RESERVA CONSTITUCIONAL DE MONOPÓLIO ESTATAL (CF, ART. 21, XII, 'c'). POSSIBILIDADE DE A UNIÃO FEDERAL OUTORGAR, POR LEI, A UMA EMPRESA GOVERNAMENTAL, O EXERCÍCIO DESSE ENCARGO, SEM QUE ESTE PERCA O ATRIBUTO DE ESTATALIDADE QUE LHE É PRÓPRIO. OPÇÃO CONSTITUCIONALMENTE

\footnotetext{
${ }^{35}$ Para um melhor aprofundamento no assunto, cf: PACHECO, José da Silva. Código Brasileiro de Aeronáutica Comentado. $4^{\mathrm{a}}$ ed. Rio de Janeiro: Forense, 2006.

${ }^{36}$ Cf. atribuições da ANAC. Disponível em: http://www.anac.gov.br/Area.aspx?ttCD_CHAVE=7. Acesso em: 30 Abr. 2011.

BRASIL. Lei n. 11.182, de 27 de setembro de 2005. Cria a Agência Nacional de Aviação Civil - ANAC, e dá outras providências. Disponível em: http://www.planalto.gov.br/ccivil_03/_ato2004-2006/2005/Lei/L11182.htm. Acesso em: 04 abr. 2011.
} 
LEGÍTIMA. CRIAÇÃO DA INFRAERO COMO INSTRUMENTALIDADE ADMINISTRATIVA DA UNIÃO FEDERAL, INCUMBIDA, NESSA CONDIÇÃO INSTITUCIONAL, DE EXECUTAR TÍPICO SERVIÇO PÚBLICO (LEI No 5.862/1972). CONSEQÜENTE EXTENSÃO, A ESSA EMPRESA PÚBLICA, EM MATÉRIA DE IMPOSTOS, DA PROTEÇÃO CONSTITUCIONAL FUNDADA NA GARANTIA DA IMUNIDADE TRIBUTÁRIA RECÍPROCA (CF, ART. 150, VI, 'a'). O ALTO SIGNIFICADO POLÍTICOJURÍDICO DESSA GARANTIA CONSTITUCIONAL, QUE TRADUZ UMA DAS PROJEÇÕES CONCRETIZADORAS DO POSTULADO DA FEDERAÇÃO. IMUNIDADE TRIBUTÁRIA DA INFRAERO, EM FACE DO ISS, QUANTO ÀS ATIVIDADES EXECUTADAS NO DESEMPENHO DO ENCARGO, QUE, A ELA OUTORGADO, FOI DEFERIDO, CONSTITUCIONALMENTE, À UNIÃO FEDERAL. DOUTRINA. JURISPRUDÊNCIA. PRECEDENTES DO SUPREMO TRIBUNAL FEDERAL. RECURSO EXTRAORDINÁRIO IMPROVIDO.'

Em verdade, a INFRAERO tem mais semelhanças com uma autarquia do que com uma empresa privada, pois foi incumbida de executar serviço público por meio de outorga legal, é também controlada na sua integralidade pelo Poder Público (sem ingerência de particulares) e, por isso, acredita-se que se arrazoa a aplicação da imunidade tributária.

\subsection{Os efeitos tributários das possíveis mudanças na estruturação da INFRAERO}

Como afirmando, para a captação de recursos, o mais provável é que se abra o capital da INFRAERO para o mercado. Assim, deixará a mesma de ser uma empresa pública para se tornar uma sociedade de economia mista.

Objetivando, portanto, atrair investimentos, a INFRAERO terá necessariamente de apresentar resultados econômicos interessantes aos particulares que, integrando a administração interna da empresa, procurarão conferir às atividades praticadas maior rentabilidade, buscando assim o lucro, como forma de auto-sustentação.

Conforme exposto, a busca do lucro não é o objetivo precípuo da prestação de um serviço público. Ainda que dotada de conteúdo econômico a atividade (capaz de gerar lucro por meio da sua exploração), frisa-se que a ingerência privada relevante (particulares com ampla participação no capital societário da empresa prestadora) perverte a finalidade do oferecimento da comodidade.

\footnotetext{
${ }^{38}$ BRASIL, Supremo Tribunal Federal. RE 363.412/BA, Rel. Min. Celso de Mello, grifo nosso. Disponível em: http://www.jusbrasil.com.br/jurisprudencia/14314484/recurso-extraordinario-re-472490-ba-stf. Acesso em: 4 abril 2011
} 
Daí, surge o seguinte questionamento: se a empresa privada prestadora de um serviço público é sempre tributada, não deveria ser também a sociedade de economia mista, cujo objetivo é o lucro?

Entende-se que o puro e simples controle majoritário da União não tem o condão de presumir a extirpação do intuito lucrativo, e a consequente aplicação da imunidade intergovernamental.

Nem mesmo o regime de monopólio estatal tem força suficiente para garantir a aplicação da imunidade tributária quando se verifica a distribuição de lucros para particulares, como assim pontifica o STF:

CONSTITUCIONAL. TRIBUTÁRIO. IMUNIDADE TRIBUTÁRIA RECÍPROCA (ART. 150, VI, A DA CONSTITUIÇÃO). IMÓVEL UTILIZADO EM ATIVIDADE SUJEITA A MONOPÓLIO DA UNIÃO. PETRÓLEO, COMBUSTÍVEIS OU DERIVADOS. OPERAÇÃO PELA PETRÓLEO BRASILEIRO S.A. - PETROBRÁS. MONOPÓLIO DA UNIÃO. INAPLICABILIDADE DA SALVAGUARDA CONSTITUCIONAL.

1. Recurso extraordinário interposto de acórdão que considerou tributável propriedade imóvel utilizada pela Petrobrás. Alegada imunidade tributária recíproca, na medida em que a empresa-agravante desempenha atividade sujeita a monopólio.

2. É irrelevante para definição da aplicabilidade da imunidade tributária recíproca a circunstância de a atividade desempenhada estar ou não sujeita a monopólio estatal. O alcance da salvaguarda constitucional pressupõe o exame (i) da caracterização econômica da atividade (lucrativa ou não), (ii) do risco à concorrência e à livre-iniciativa e (iii) de riscos ao pacto federativo pela pressão política ou econômica.

3. A imunidade tributária recíproca não se aplica à Petrobrás, pois: 3.1. Trata-se de sociedade de economia mista destinada à exploração econômica em benefício de seus acionistas, pessoas de direito público e privado, e a salvaguarda não se presta a proteger aumento patrimonial dissociado de interesse público primário; 3.2. A Petrobrás visa a distribuição de lucros, e, portanto, tem capacidade contributiva para participar do apoio econômico aos entes federados; 3.3. A tributação de atividade econômica lucrativa não implica risco ao pacto federativo.

4. Inexiste violação do dever de prestação jurisdicional, quando a decisão é fundamentada, ainda que com o resultado não concorde a parte.

5. Aplicabilidade da orientação firmada na Súmula 279/STF ao reconhecimento da titulariedade do bem tributado. Agravo regimental ao qual se nega provimento ${ }^{39}$.

A operação de terminais em aeroportos por empresas $\operatorname{privadas}^{40}$ já cria uma expectativa de concorrência referente a essa atividade. Mesmo caracterizada como serviço

39BRASIL, Supremo Tribunal Federal. RE 290956/SP, Rel. Min. Joaquim Barbosa, grifo nosso. Disponível em: http://www.jusbrasil.com.br/jurisprudencia/9119305/agreg-no-recurso-extraordinario-re-290956-sp-stf. Acesso em: 28 Abr. 2011.

${ }^{40}$ Tal medida já foi tomada também se concedendo a exploração de áreas comerciais dos aeroportos a empresas privadas. Cf. notícia da Folha de São Paulo. Disponível em: http://200.175.180.15/webclipping/openantt/noticia.php?pg=11\&id_cliente=75\&id_edicao=12\&data=29/04/201

1. Acesso em: 30 Abr. 2011. 
público, desde já se pode prever repercussões no mercado, i.e., quem prestar o serviço com melhor eficiência concentrará mais consumidores e perceberá maiores lucros ${ }^{41}$.

Enfim, uma vez aberto o capital da INFRAERO e outras empresas também atuando, mesmo que especializadamente, no setor de infraestrutura aeroportuária, não será mais justificada a imunização da referida empresa com fulcro no art. 150, VI da CR/88.

\section{Conclusões}

A abertura de capital da INFRAERO, se confirmada a sua realização, incutirá efeitos em seu tratamento fiscal. O presente artigo procurou prever uma antecipação de resultados ${ }^{42}$, assentado-se primordialmente na jurisprudência do $\mathrm{STF}^{43}$.

Como afirmando, ainda que prestando serviço público, a INFRAERO, se distribuir lucro a particulares, terá de se submeter à exação de impostos, em vista do princípio da livre concorrência.

Nesse sentido, não ficaria mais relevante o regime de monopólio estatal da atividade para o exame da aplicabilidade da imunidade tributária recíproca, pois o particular acionista não pode se beneficiar da referida prerrogativa constitucional e assim obter um lucro maior.

Desta feita, a assunção do risco pela INFRAERO de distribuir de lucros aos seus acionistas, quando transformada em sociedade de economia mista, derrogaria o perigo que a tributação poderia trazer para o pacto federativo. Assim, ao deixar seu patrimônio, renda e serviços voltados para interesses além dos fins públicos, a INFRAERO apresentará capacidade contributiva.

\footnotetext{
${ }^{41}$ Mesmo com a adoção dessa divisão de atribuições de mesma natureza entre a INFRAERO e as empresas privadas pelo Poder Público (mediante concessões da ANAC), acredita-se que somente com a abertura do capital da INFRAERO é que a imunidade da empresa possa vir a ser derrogada em juízo.

${ }^{42}$ Muito embora só o sistema jurídico coaja os Tribunais à decisão, estes, constituindo o centro do sistema jurídico, estão defesos a recusar a prestação jurisdicional. LUHMANN, Niklas, A posição dos tribunais no sistema jurídico, traduzido por Peter Naumann e revisado por Vera Jacob de Fradera, Porto Alegre: Revista Ajuris, n. 49, ano XII, jul., 1990, p.160. Desta feita, é certo que o usufruto da prerrogativa constitucional da imunidade tributária intergovernamental pela INFRAERO venha a ser revisto pelos tribunais.

${ }^{43}$ Antecipação melhor se terá com o julgamento do Recurso Extraordinário (RE) 594015/SP, interposto pela Petrobras (sociedade de economia mista com ampla participação privada no capital social) contra decisão do Tribunal de Justiça do Estado de São Paulo que a considerou devedora do Imposto Predial e Territorial Urbano (IPTU) incidente sobre imóvel localizado no Porto de Santos. A decisão refletirá o mais recente posicionamento do STF sobre a hipótese aqui defendida, mas é bem provável que a Suprema Corte terá no referido julgamento o mesmo entendimento que teve no RE 290956/SP.
} 
As mudanças na estrutura da INFRAERO não deixam intacto o cenário pelo o qual o STF a garantiu a aplicação da imunidade tributária ${ }^{44}$, pois as receitas da INFRAERO obtidas com a exploração do serviço público que figura como sua destinação institucional não só pertencerão à União, mas também servirão em benefício de seus acionistas. Esta conclusão se dá, como foi demonstrado, pela importância que o STF dá ao princípio da livre concorrência.

Em notícia recente, Rogério Coimbra, o secretário de Política Regulatória da Secretaria de Aviação Civil (SAC) divulgou recentemente o modelo adotado com o fim de turbinar os aeroportos brasileiros, enunciando que concessões serão feitas por meio de sociedades de propósito específico (SPEs), constituídas por empresas privadas que se encarregarão da gestão desses aeroportos e pela Infraero, que terá participação até $49 \%$ em cada aeroporto.

A Presidente da República, ao comentar as concessões de aeroportos à iniciativa privada, disse que a Infraero levará um "choque de competitividade" . Ainda deixou claro que pretende abrir o capital da referida empresa; corroborando, assim, com a expectativa aqui levada a efeito.

Assim, vê-se que o Poder Executivo encontra-se inclinado a transformar a INFRAERO numa sociedade de economia mista. É de se notar que talvez esses agentes políticos não estejam levando em conta a possível mudança no tratamento fiscal.

Concluímos então que os argumentos alegados para o deferimento da garantia constitucional pugnam pelo indeferimento da mesma com a aludida reforma ao levarmos em consideração a fundamentação dos julgados do Supremo Tribunal Federal.

Em suma, resta ao Poder Público (mediante lei específica, evidentemente) a opção de transformar a INFRAERO em sociedade de economia mista. Se assim a fizer, deverá ponderar as consequências dessa faculdade.

\section{REFERÊNCIAS:}

\footnotetext{
${ }^{44}$ Uma saída viável, talvez, seria a cisão da referida empresa, desvinculando as atividades que não objetivam propriamente o lucro daquelas que se pretende atrair investimentos. Desta maneira, ficaria exonerada de recolher tributos aquela empresa que concentraria o patrimônio essencial à prestação do serviço público em questão. 45

Notícia disponível em: www.fiesp.com.br/agencianoticias/2011/06/14/concessao_aeroportos_detalhada_encontro_logistica. Acesso em 05 de jul. 2011.

${ }^{46}$ Notícia disponível em: http://www.jb.com.br/pais/noticias/2011/05/31/dilma-diz-que-infraero-levara-choquede-competitividade/. Acesso em 05 de jul. 2011.
} 
AMARO, Luciano. Direito Tributário Brasileiro. 12aed., São Paulo: Saraiva, 2006.

BANDEIRA DE MELLO, Celso Antônio. Curso de Direito Administrativo. São Paulo: Malheiros. $26^{\mathrm{a}}$ ed., 1102 p. 2009.

BANDEIRA DE MELLO, Celso Antônio. Prestação de Serviços Públicos e Administração Indireta, p.83, 1973.

BRASIL. Constituição Federal de 1988, de 25 de outubro de 1988. Disponível em: www.planalto.gov.br/ccivil_03/Constituicao/Constituiçao.htm. Acesso em: 04 abril 2011

BRASIL, Supremo Tribunal Federal, RE 472490/BA, Min. Relator Dias Toffoli, julgado em 24/04/2010, in DJ de 31/05/2010.

BRASIL, Supremo Tribunal Federal, RE 363.412/BA, Rel. Min. Celso de Mello, julgado em 21/03/2007, in DJ de $28 / 03 / 2007$.

BRASIL, Supremo Tribunal Federal, RE 253472/SP, Min. Relator Marco Aurélio, red. p/ o acórdão Min. Joaquim Barbosa, in informativo no 602 de 25/08/2010.

BRASIL, Supremo Tribunal Federal, RE 290956/SP, Min. Relator Joaquim Barbosa, julgado em 06/06/2010, in DJ de 07/05/2010.

BRASIL. Decreto-Lei 200, de 25 de fevereiro de 1967. Dispõe sobre a organização da Administração Federal, estabelece diretrizes para a Reforma Administrativa e dá outras providências. Disponível em: http://www.planalto.gov.br/ccivil/decreto-lei/Del0200.htm. Acesso em: 25 mar. 2011.

BRASIL. Lei n. 5.862 de 12 de dezembro de 1972. Autoriza o Poder Executivo a constituir a empresa pública denominada Empresa Brasileira de Infraestrutura Aeroportuária - INFRAERO, e dá outras providências. Disponível em: http://www.planalto.gov.br/ccivil_03/Leis/1970-1979/L5862.htm. Acesso em: 04 abr. 2011.

BRASIL. Lei n. 11.182, de 27 de setembro de 2005. Cria a Agência Nacional de Aviação Civil - ANAC, e dá outras providências. Disponível em: http://www.planalto.gov.br/ccivil_03/_ato2004-2006/2005/Lei/L11182.htm. Acesso em: 04 abr. 2011.

BRASIL. Tribunal Regional Federal da 5ª Região. Apelação Cível 364578/ CE. Des. Relatora Amanda Lucena, julgado em 03/09/2009, in DEJ de 18/09/2009, p.515.

HABERMAS, Jürgen, 1929- Direito e democracia: entre facticidade e validade, volume I/Jürgen Habermas; tradução: Flávio Beno Siebeneichler. - Rio de Janeiro: Tempo Brasileiro, 1997.

MUKAI, Toshio. Direito Administrativo e Empresas do Estado. Rio de Janeiro: Forense, 1984, p.123. 